\title{
TOO MUCH FEAR FOR RADIOACTIVE CONTAMINATION OF SEAWATER
}

\section{॥. J. Goudriaan - Emeritus professor WUR, Wageningen, The Netherlands - DOI: https://doi.org/10.1051/epn/2019102}

Radioactive contamination of seawater has often caused concern, for example about releases from Sellafield and Le Havre and later about the Fukushima disaster. Repeated reporting has contributed to the general feeling that the sea is particularly sensitive to radioactive contamination (Greenpeace,1998). This is not the case, it is rather the opposite. Marine life is much better protected against radioactive contamination than life on land. This protection is due to three natural factors: shielding, dilution and isotope competition. 


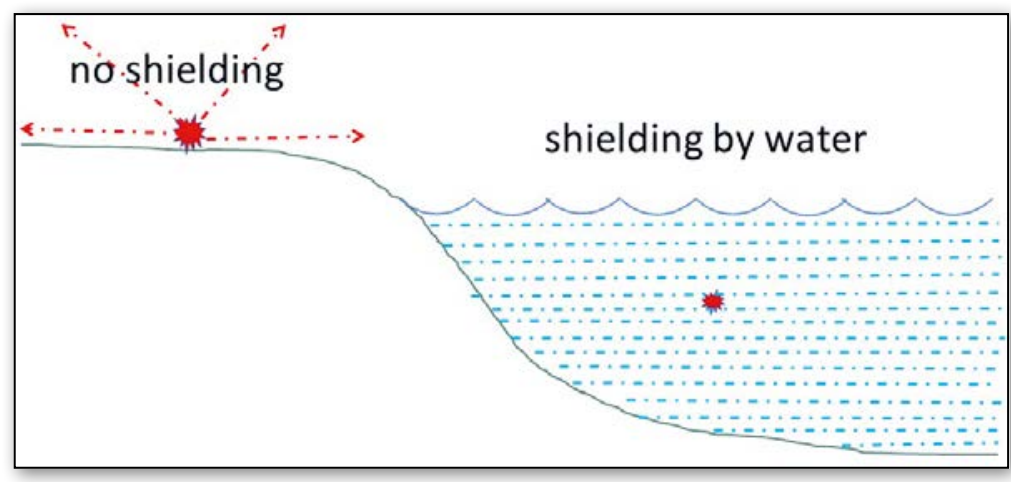

$\triangle$ FIG. 1:

Radioactivity

in water is almost perfectly shielded,

as opposed to radioactivity on land. The red arrows represent the range of the radioactivity.

v FIG. 2: Fallout in sea is much more diluted than on land as indicated by the colour dilution in sea.

\section{Shielding}

Water itself shields radiation. It does so much better than air, simply because its density is about 1000 times larger. Not all radioactive radiation is the same. For simplicity here only the three major types are considered: alpha-, beta- and gamma radiation. Alpha radiation (which is identical to the nucleus of helium consisting of 2 protons and 2 neutrons) is emitted in the decay chain of unstable heavy elements such as uranium and plutonium. It is emitted with such high energy (around $5 \mathrm{MeV}$ ) that serious damage in biological and human tissue may occur, notably in the DNA of cell nuclei. If such damaged cells survive, multiple undesirable mutations may occur in subsequent mitosis. The interaction of alpha radiation with matter is so strong that it loses its energy very quickly and so it does not penetrate deeper than one tenth of a millimetre, whether in water or in even a dead upper epidermis. However, inside living tissue such as a mucous membrane or a vein, alpha radiation is 20 times as harmful as beta or gamma radiation for the same amount of absorbed energy. Therefore it is assigned a radiation weight factor of 20 . Beta radiation (in fact electrons) and gamma radiation (photons) usually carry less energy and their interaction with matter is much smaller, so that they can penetrate much deeper. Yet 10 meters of water is usually enough to block them. This means that any radioactive source under water loses danger if it is shielded by more than 10 meters of water. This fact is one of the reasons why large pools of water are being used to store containers with high level radioactive waste. No radiation can reach us from sea emitted by sources at a depth greater than $10 \mathrm{~m}$. Possible dissemination from sea to man, by

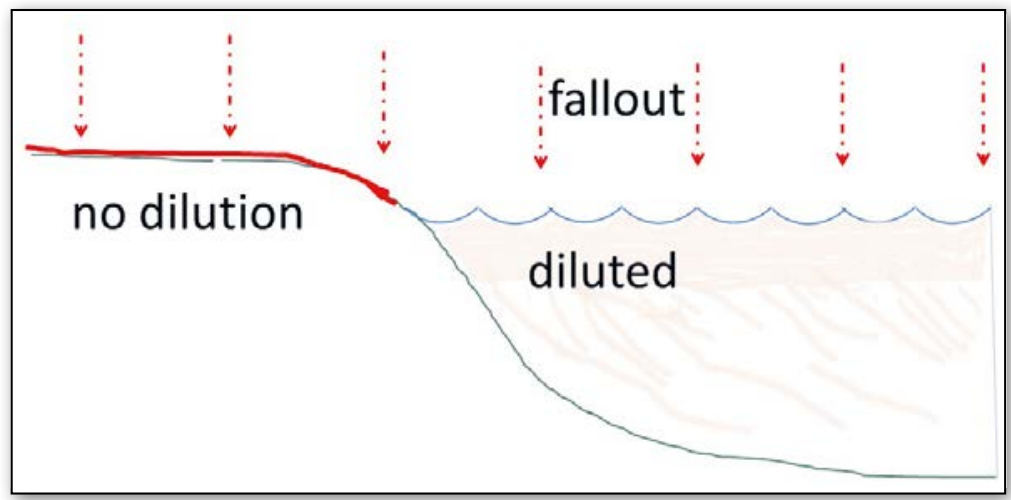

fishery for example, will be dealt with below.

Of course, fresh water and seawater are alike in this shielding property, but the amount of fresh water is minute in comparison to the amount of seawater.

\section{Dilution}

This difference in size brings us to the second mechanism which is that the mass of the ocean is enormous in comparison to the mass of the atmosphere or to the mass of the land biota. Any radioactive material will therefore be much more effectively diluted in the sea than a similar amount on land. Radioactivity in sea will much faster drop below the natural background radiation than on land. Even the huge radioactive contamination by the thermonuclear explosions in the sixties that have released about one hundred times more radioactivity than Chernobyl, is nowadays diluted to a radioactivity of plutonium that does not exceed $0.1 \mathrm{~Bq} \mathrm{~m}^{-3}$ (Hirose, 2009) (Box 1). This level is negligible in comparison to the natural radioactivity of seawater of $12000 \mathrm{~Bq} \mathrm{~m}^{-3}$ (mainly from radioactive potassium ${ }^{40} \mathrm{~K}$ ).

${ }^{40} \mathrm{~K}$ is a natural component of potassium (at $0.012 \%$ ), also in seawater which contains about $400 \mathrm{~g}$ of $\mathrm{K} \mathrm{per}^{3}$. Even if the effective radiation dose of an ingested alpha emitter such as plutonium is much larger than that of beta radiation, the radiation dose due to plutonium at the mentioned level is ten thousand times smaller than the background level. The beta radiation of ${ }^{40} \mathrm{~K}$ penetrates deeper than alpha radiation: some tens of centimetres. Therefore, it can penetrate the human body from outside, although much less than the gamma radiation from the same radionuclide. Interestingly, the potassium concentration in our body is eight times as high as that in seawater, and so in a crowd we irradiate each other eight times stronger than while swimming in the sea!

Another illustration of the effectiveness of dilution in the ocean is the course of events in Fukushima. The total emission there has been about one tenth of that in Chernobyl. A considerable part of this release ended up in the sea, largely by outflow of cooling water. Because of this, the radioactivity of the seawater near Fukushima peaked at $25 \mathrm{~Bq} /$ litre during the first weeks after the disaster, mainly from caesium, both ${ }^{137} \mathrm{Cs}$ and ${ }^{134} \mathrm{Cs}$ (Grossman, 2012). This looks like being serious, but in fact it amounts to only twice the natural radioactivity of seawater and a quarter of that of the human body! "Alarming" reporting about radioactive caesium near the Californian coast does exist, but the levels were so low that these findings are a good reason for admiration of the detection potential rather than for any worry.

\section{Isotope competition}

Radioactive iodine, caesium and strontium are among the most feared and most dangerous radioactive substances released during a nuclear accident. It is precisely these elements that encounter their non-radioactive 
counterparts abundantly present in seawater (Table 1). By sheer number these harmless isotopes largely outcompete the radioactive contaminants in the process of biotic uptake.

\begin{tabular}{|l|c|c|}
\hline & CONCENTRATION & QUANTITY PER KM \\
\hline lodine & $5010^{-9} \mathrm{~g} / \mathrm{g}$ & $5010^{3} \mathrm{~kg}$ \\
Caesium & $210^{-9} \mathrm{~g} / \mathrm{g}$ & $210^{3} \mathrm{~kg}$ \\
Strontium & $1310^{-6} \mathrm{~g} / \mathrm{g}$ & $1310^{6} \mathrm{~kg}$ \\
Calcium & $45010^{-6} \mathrm{~g} / \mathrm{g}$ & $45010^{6} \mathrm{~kg}$ \\
Potassium & $40010^{-6} \mathrm{~g} / \mathrm{g}$ & $40010^{6} \mathrm{~kg}$ \\
Radioactivity & $12 \mathrm{~Bq} / \mathrm{litre}$ & $12 \mathrm{TBq}$ \\
\hline
\end{tabular}

$\triangle$ Table 1.: Contents in seawater

The mechanism of the protective action of seawater is identical to that of medical pills of iodine which are recommended in case of a nuclear accident. The rationale of this protective measure is to saturate the thyroid with Iodine so that it will no more take up any radioactive iodine.

Iodine shortage is much more frequent in inland regions far from the sea, where seafood is hard to obtain, than in coastal regions. Consequently, the human population in such regions is more vulnerable to radioactive ${ }^{131} \mathrm{I}$.

In the unfortunate case that radioactive iodine finds its way to the sea, it can hardly cause any damage because its quantity is minute in comparison to the stable Iodine already present in seawater. As little as $8000 \mathrm{~m}^{3}$ of seawater (equivalent to a large swimming pool) already contains $400 \mathrm{~g}$ of iodine, the total quantity released by Chernobyl.

In the case of caesium and strontium a similar argument applies. In Chernobyl $26 \mathrm{~kg}$ of ${ }^{134} \mathrm{Cs}$ and ${ }^{137} \mathrm{Cs}$ was released with a radioactivity of $85 \mathrm{PBq}$ and ${ }^{90} \mathrm{Sr}$ with a radioactivity of $10 \mathrm{PBq}$. Both isotopes have a half value time of about 30 years, which makes them dangerous for many decades. Chemically, caesium is like potassium that is mainly present in muscles and nerves and strontium is more like calcium, the major constituent of bones. Caesium and strontium will therefore be transported to these tissues. Upon decay, ${ }^{137} \mathrm{Cs}$ emits both beta- and gamma radiation (with an energy between 0.5 and $0.7 \mathrm{Mev}$ ), upon conversion to stable barium. ${ }^{40} \mathrm{~K}$ releases radiation with practically twice the energy ( $1.3 \mathrm{MeV}$ beta with $89 \%$ occurrence and $1.46 \mathrm{MeV}$ gamma with $11 \%$ occurrence). This means that the specific radiation danger per $\mathrm{Bq}$ of ${ }^{137} \mathrm{Cs}$ is half of that of ${ }^{40} \mathrm{~K}$, the main natural source of radiation in seawater. Using the data in Table 1, it is easily shown that the total radioactivity of ${ }^{137} \mathrm{Cs}$ released by Chernobyl is equal to the amount that is naturally present in $7000 \mathrm{~km}^{3}$ of seawater. This volume of water occupies a surface area of $150 \times 150 \mathrm{~km}$ for a well-mixed surface layer of $300 \mathrm{~m}$ above the thermocline, a much smaller area than what has been contaminated after Chernobyl.
In this scenario, radioactive caesium would make up a fraction of $1.8 \mathrm{ppm}$ (part per million) of the stable caesium already present in seawater. In addition, the potassium concentration in seawater is two hundred thousand times higher than that of the stable caesium. This all means that radio-active caesium has almost no chance to be taken up, which is why the radioactive contamination of sea fish in the waters near Fukushima remained very small (UNSCEAR, 2013).

The concentration of strontium in seawater (Table 1) is still a lot higher than that of caesium so that ${ }^{90} \mathrm{Sr}$ gets even less opportunity to be taken up. In addition, it has also to compete with calcium that is present in seawater in high concentration as well.

On land, especially in acidic, oligotrophic (nutrient-poor) regions, the situation is exactly the opposite. In case of shortage of calcium and potassium, their substitutes strontium and caesium are eagerly taken up, whether radioactive or not. In many regions of northern Europe where much of the Chernobyl fallout precipitated, precisely such poor soil conditions are prevalent.

Upon consumption of radioactively contaminated seafood, the protecting competition mechanism does not work, because we do not drink seawater. Fortunately, in practice the risks appear to be small. According to Chen (2013) even a copious consumption of the most contaminated fish in the Fukushima region would have caused a negligible radiation dose. Table $\mathrm{C} 18$ in the UNSCEAR report of 2013 about Fukushima shows that the consumption of fish in the region was responsible for less than one thousandth of the total radiation dose of the population. Considering that more than half of the total quantity of escaped radioactive caesium found its way to the sea, the ensuing exposure of man has been exceedingly small. From the sea it is not radioactive caesium or strontium that contributes most, but polonium of natural origin.

\section{Polonium}

${ }^{210} \mathrm{Po}$ is continually formed in the decay chain of uranium $\left.{ }^{(238} \mathrm{U}\right)$, after radon and before lead. It is therefore of natural origin. Radon gas is a notorious source of alpha radiation as it is released by most soil types and non-organic building materials. Several isotopes of radon exist, but the

\section{few competing isotopes}

fresh water

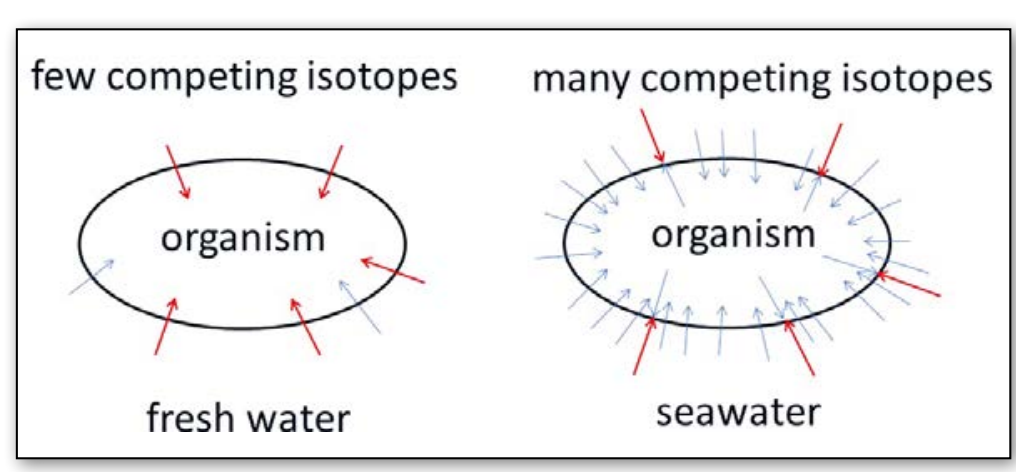

vFIG. 3:

In seawater competing nonradioactive isotopes hamper uptake of radioactive I, Cs, and Sr. This mechanism is lacking in fresh water and on land. 
only important one is ${ }^{222} \mathrm{Rn}$ of the decay chain of ${ }^{238} \mathrm{U}$. It has a half value time of 3.8 days, which is long enough to accumulate in poorly ventilated rooms. Being a gas, it can be inhaled and exhaled without causing radiation damage in the lungs but the real problem is that it decays (via short lived descendants) to lead $\left({ }^{210} \mathrm{~Pb}\right)$. This element adheres easily to aerosols and fine dust particles that may stay in the lungs, the more so because ${ }^{210} \mathrm{~Pb}$ has a relatively long half value time of 22 years. On its turn it decays to ${ }^{210} \mathrm{Po}$ which is the dangerous one. It is an alpha emitter with a short half value time of 138 days, decaying to the stable lead isotope ${ }^{206} \mathrm{~Pb}$. One could have thought that because of this short half value time, polonium should be present in very small quantities and therefore not be dangerous. The first is true, but the second is not. If one thinks of the decay chain of uranium as a series of cascades, it is easily understood that in the long run the flow through each pool should be the same, whatever the size of the pool. Thus, the total global decay rate of each element in the chain is the same in terms of Bq: they are in secular equilibrium. Radon, being a gas, is widely spread and so is its successor polonium. Both in air and in water, ${ }^{210} \mathrm{~Pb}$ and ${ }^{210} \mathrm{Po}$ attach to fine particles and readily precipitate to the soil or to the bottom of the water. A considerable amount of polonium in seawater is taken up by bacteria and microplankton, thus entering the marine food chain (Carvalho et al., 2017). It is also omnipresent on the seafloor where it quickly finds its way into the marine food chain, helped by the high chemical affinity of proteins for polonium (Hosseini et al., 2008; Carvalho, 2018). Seafood has an important share in the Japanese diet and it contributes $0.80 \mathrm{mSv}$ per year to the average human radiation dose in Japan, largely due to polonium. The average radiation dose from food is only $0.12 \mathrm{mSv}$ per year worldwide (Ota et al.,2009). An instructive visual representation of the contribution of various sources of radioactivity to the annual radiation dose for humans is given by the Radiation Dose Chart https://xkcd.com/ radiation/. Bio-accumulation of polonium also explains the large internal radiation dose in dolphins which was found to be even three orders of magnitude higher than

\section{BOX}

One Becquerel (Bq) means one radioactive decay event per second, irrespective of the type of nucleus or type of radiation or particle released. The dose absorbed by an organism is expressed in the unit Gray (Gy) in J/kg. To allow for the health effects on humans of different types of radiation in different organs, the unit Sievert (Sv) is used. One Sv carries with it a 5.5\% chance of eventually developing cancer, assuming a linear effect with zero threshold. The natural background radiation causes an annual dose of $2.4 \mathrm{mSv}$. In the conversion from Bq to Sv many factors are involved (ICRP, 2006). the average radiation dose in man (Malta and Carvalho, 2011). In dolphins $97 \%$ of their radiation dose came from polonium against only $3 \%$ from ${ }^{40} \mathrm{~K}$ and ${ }^{14} \mathrm{C}$.

Above I used the background radiation of ${ }^{40} \mathrm{~K}$ to find out how much ocean volume would be needed if one were to dilute the total Chernobyl fallout to the same level. In view of the much larger effect of polonium, this calculation was on the safe side.

\section{Conclusion}

The marine biosphere is much less sensitive to radioactive contamination than the terrestrial biosphere. This is due to: (1) shielding by water, (2) the huge mass and volume available for dilution, and (3) suppression by non-radioactive isotopes that are omnipresent in seawater in high concentrations. Natural radioactivity, notably from polonium, is a much larger contributor to the radiation dose of sea life and indirectly also to that of humans than man-made radioactivity.

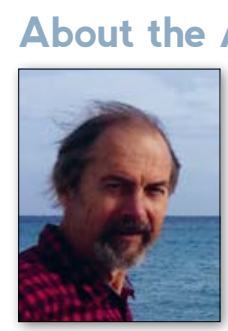

uthor

Jan Goudriaan, born 1946, MSc degree in 1970 in Physics at the Technical University of Delft, The Netherlands. PhD degree in 1977 at WUR, Wageningen. Research on the global carbon cycle as affected by terrestrial vegetation and the ocean. Akzo-Nobel prize in 1992.

\section{References}

[1] Y. Chen, Evaluation of radioactivity concentrations from the Fukushima nuclear accident in fish products and associated risk to fish consumers. Radiation Protection Dosimetry. 2013 Nov; 157(1): 1-5.

[2] K. Hirose, Journal of nuclear and radiochemical sciences 10-1, 7 (2009).

[3] Greenpeace, 1998. Report on the world's oceans.

[4] ICRP, 2006. Assessing Dose of the Representative Person for the Purpose of the Radiation Protection of the Public. ICRP Publication 101a. Ann. ICRP 36 (3).

[5] UNSCEAR, 2013. Sources, effects and risks of ionizing radiation. Annex A. Levels and effects of radiation exposure due to the nuclear accident after the 2011 great east-Japan earthquake and tsunami.

[6] A. Hosseini, H. Thorring, J.E. Brown, R. Saxen and E. llus, Journal of environmental radioactivity 99, 1408 (2008).

[7] F. Carvalho, S. Fernandes, S. Fesenko, E. Holm, B. Howard, P. Martin, M. Phaneuf, D. Porcelli, G. Pröhl and J. Twining. The environmental behaviour of polonium. IAEA Technical Report Series 484, IAEA, Vienna (2017).

[8] F.P. Carvalho, Journal of environmental radioactivity 186, 124 (2018).

[9] M. Malta and F.P. Carvalho, Journal of environmental radioactivity 102,473 (2011).

[10] T. Ota, T. Sanada, Y. Kashiwara, T. Morimoto and K. Sato, Japanese Journal for Health Physics 44-1, 80 (2009). 